\title{
Integrated Design and Analysis of RF Heating and Current Drive Systems*
}

P. M. Ryan, M. D. Carter, R. H. Goulding, D. B. Batchelor, E. F. Jaeger, D. C. Stallings, C. Y. Wang, F. W. Baity, G. L. Bell, T. S. Bigelow, A. C. England, G. R. Hanson, G. R. Haste, D. J. Hoffman, M. Murakami, D. A. Rasmussen, J. B. Wilgen, Oak Ridge National Laboratory, Oak Ridge, Tennessee 37831-8071

J. H. Rogers, R. Majeski, G. Schilling, J. R. Wilson, and the TFTR ICH Team Princeton Plasma Physics Laboratory, Princeton, NJ;

V. Bhatnagar, M. Bures, A. Kaye, D. Start, T. Wade and the JET ICH Team, JET Joint Undertaking, Abingdon, UK.

Y. L. Ho and W. Kruger, SAIC-McLean, VA

\begin{abstract}
The design, analysis, and performance evaluation of rf power systems ultimately requires accurate modeling of a chain of subsystems starting with the rf transmitter and ending with the power absorption in the plasma. A collection of computer codes is used at ORNL to calculate the plasma loading and wave spectrum for a threedimensional if antenna, the transmission/reflection properties of the Faraday shield and its effect on the electrical characteristics and phase velocity of the antenna, the internal coupling among antenna array components and the incorporation of the antenna array into a transmission line model of the phase control, tuning, matching, and power distribution system. Some codes and techniques are more suited for the rapid evaluation of system design progressions, while others are more applicable to the detailed analysis of final designs or existing hardware. The interaction of codes and the accuracy of calculations will be illustrated by the process of determining the plasma loading as a function of phasing and density profiles for the TFTR ICRH antennas and comparing the results to measurements. An example of modeling a complex antenna geometry will be the comparison of calculations with the measured electrical response of a four-strap mockup of the JET A2 antenna array which was loaned to ORNL by the JET ICRH team.
\end{abstract}

\section{Design and Analysis of RF Systems}

Design of an rf system for fusion experiments, including power transmitters, power distribution and matching network, antenna launchers, and the wave interaction with the target plasma, is a somewhat different activity from the analysis of such a system. The numerical tools used for system design emphasize speed, modularity, and flexibility to permit rapid evaluation of many design concepts. Interactive codes which allow parameter variation and system configuration modifications are highly desirable. In the initial stages of system design, independent control of variables aids in the understanding of the total system response and identification of crucial parameters. The desire for total system evaluation implies a minimization of interfaces with other codes.

Evaluation of a system that is either already in existence or close to its final design stage puts a premium on detail and accuracy, often at the expense of speed

*Research managed by the Office of Fusion Energy, U.S. Department of Energy, under contract DE-AC05-84OR21400 with Martin Marietta Energy Systems, Inc.

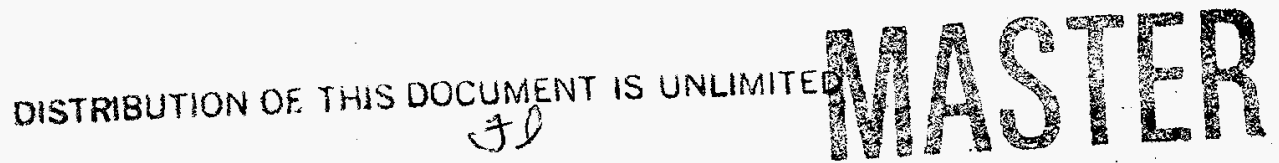




\section{DISCLAIMER}

This report was prepared as an account of work sponsored by an agency of the United States Government. Neither the United States Government nor any agency, thereof, nor any of their employees, makes any warranty, express or implied, or assumes any legal liability or responsibility for the accuracy, completeness, or usefulness of any information, apparatus, product, or process disclosed, or represents that its use would not infringe privately owned rights. Reference herein to any specific commercial product, process, or service by trade name, trademark, manufacturer, or otherwise does not necessarily constitute or imply its endorsement, recommendation, or favoring by the United States Government or any agency thereof. The views and opinions of authors expressed herein do not necessarily state or reflect those of the United States Government or any agency thereof. 


\section{DISCLAIMER}

Portions of this document may be illegible in electronic image products. Images are produced from the best available original document. 
and flexibility. The codes used for analysis should be able to incorporate available measurements as inputs and to calculate outputs that can be easily compared with measurable quantities. Ideally, codes should not be machine specific but applicable to a wide range of experimental configurations.

\section{Numerical Codes Presently in Use at ORNL}

Fig. 1 illustrates a set of if codes routinely used at ORNL, or in conjunction with collaborations, for the design and analysis of ion cyclotron heating and current drive systems on fusion experiments. This is, of course, only a small subset of such codes extant in the rf/fusion community, but it serves to illustrate the interfaces and areas of overlap in the design and evaluation of a system.
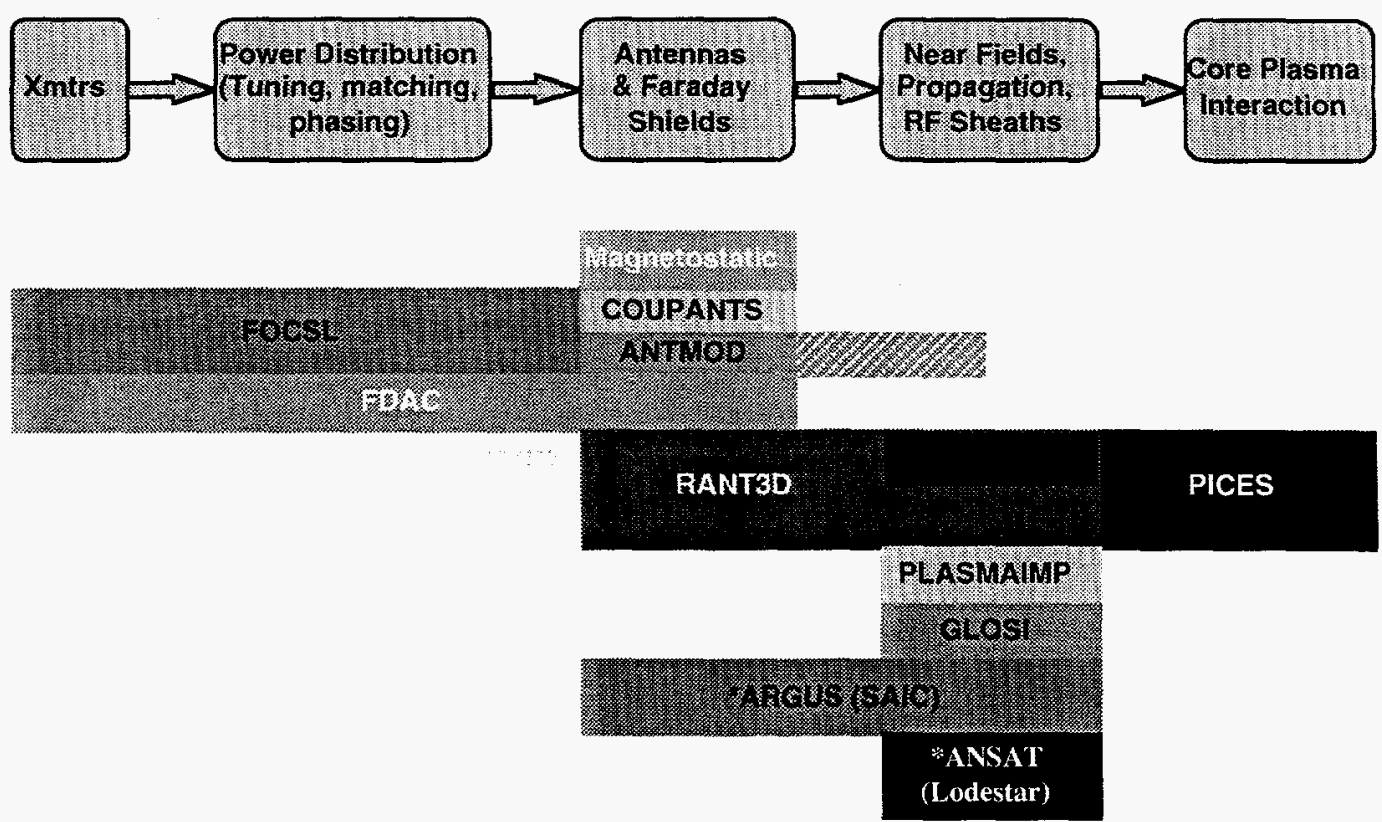

Fig. 1. An illustration of the domains of application and the interfaces of a representative set of codes used to design and analyze if systems.

An important block of numerical tools are the coupled transmission line codes of FOCSL[1], COUPANTS[2], ANTMOD[3], and FDAC[4], whose domain of application extends from the transmitters to the antenna/plasma interface. COUPANTS models the antenna as a coupled, sectionalized transmission line, each section using inductive and capacitive matrices to define its interaction with other sections of the antenna structure. ANTMOD uses the same model and parameters, but solves for the antenna voltages and currents by direct matrix inversion rather than using an iterative technique. Both codes output scattering $(\mathrm{S}$ parameter) matrices as their interface with FOCSL; input parameters come from magnetostatic analyses [5] for the coupling matrices and from RANT3D for the plasma loading.

FOCSL models the rf system from the transmitters to the antenna ports and includes all the tuning/matching components as well as the power decouplers. It was developed to model the JET ion cyclotron heating (ICH) power distribution system and the code itself needs to be modified to accommodate other system 
configurations. The recently developed design code, FDAC, specifies system configurations by means of an easily modified data set. FDAC can model the entire system from the antenna/plasma interface to the transmitters for simple antenna geometries. For asymmetric antennas with internal coupling, FDAC can be interfaced with the antenna scattering parameters calculated by ANTMOD.

The antenna plasma interaction is modeled with RANT3D[6], which solves Maxwell's equations in Fourier space using rectangular waveguide basis sets. Its object oriented code structure allows complex three-dimensional (3D) structures to be built from nested waveguide sections while imposing $\mathbf{E}$ and $\mathbf{B}$ matches at the waveguide interfaces. The final match is made to a plasma impedance matrix which is generated by PLASMAIMP[7] or GLOSI[8] . RANT3D can also use its field solutions at the plasma interface as input to PICES[9], a 3D full wave plasma code used to calculate the detailed if interaction with the target plasma.

Another antenna analysis code coming into more widespread use is ARGUS[10], a 3D electromagnetic code developed by SAIC. Its calculations of antenna vacuum fields have shown good agreement with measurements and the evaluation of its plasma loading predictions are in progress. It is particularly useful in its ability to calculate the self-consistent electromagnetic fields in the vicinity of the Faraday screen. These fields are used as input to ANSAT[11], a code developed by Lodestar to compute if sheath voltages and impurity production at plasma facing surfaces.

\section{TFTR Bay M Antenna Loading Analysis}

An example of the interaction between antenna codes and circuit models is the analysis of the plasma loading measurements made on the TFTR Bay $M$ Antenna[12]. The Bay $M$ antenna consists of two end-fed, center-grounded straps separated by a slotted septum; the two ends of each strap are fed $180^{\circ}$ out of phase by a resonant loop of transmission line tapped at a high impedance point[13]. Measured quantities are the power fed to the antenna tap point (forward and reflected voltages) and the voltages measured near the top and bottom of each strap. The equivalent series resistance $R_{S}$ of the antenna is defined in terms of the measured power and the maximum antenna current. This is in distinction to the often used coupling resistance $\mathrm{R}_{\mathrm{c}}$, defined as terminating resistance of the antenna feed line needed to duplicate the VSWR on that line.

The antenna is modeled as a lossy transmission line, with inductance, capacitance, and resistance per unit length $\left(\mathrm{L}^{\prime}, \mathrm{C}^{\prime}, \mathrm{r}^{\prime}\right)$ defined for each section of the line. The mutual inductance and phase difference between straps is included in the $\mathrm{L}^{\prime}$ and $\mathbf{r}^{\prime}$ for the strap sections. In addition to the ohmic vacuum losses $\mathbf{r}^{\prime}$, the plasma loading along the strap is represented by $R_{p}^{\prime}$ and $X_{p}^{\prime}$, the real and imaginary power per unit length calculated by RANT3D. These values are modified by the Faraday shield transmission factor (and in the case of 2D analysis, by an effective length correction factor for the end effects) as measured or calculated by the magnetostatic codes and inserted into the circuit model to obtain $\mathbf{R}_{\mathbf{s}}$.

The keys to accurate calculation of the loading resistance are knowledge of the circuit parameters described above, a 3D model of the antenna so that antenna return currents and their effect on the plasma can be properly handled, and plasma 
density profiles in the immediate vicinity of the antenna. The geometry used by RANT3D is shown in Fig. 2. The recesses surrounding the antenna cavity affect the plasma loading and power spectrum by localizing the antenna return currents in the antenna frame. The proper projection of the solid septum in this model was found by matching the interstrap coupling coefficient to that calculated by a 3D magnetostatic model with a slotted septum. The plasma density profile (Fig. 3 ) was measured by a microwave reflectometer[14] located in the nearby Bay $\mathrm{K}$.

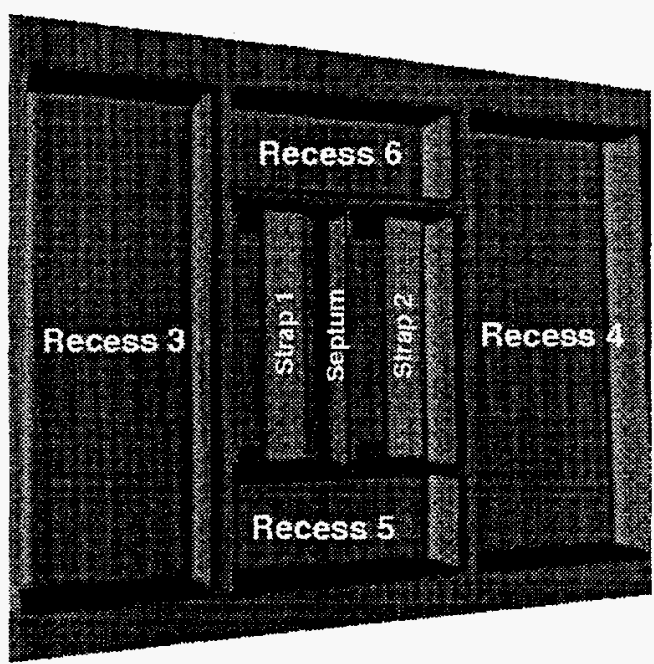

Fig. 2. RANT3D model of the TFTR Bay M antenna geometry.

TFTR R scan, Bay $M, 0 / \pi$ Phasing

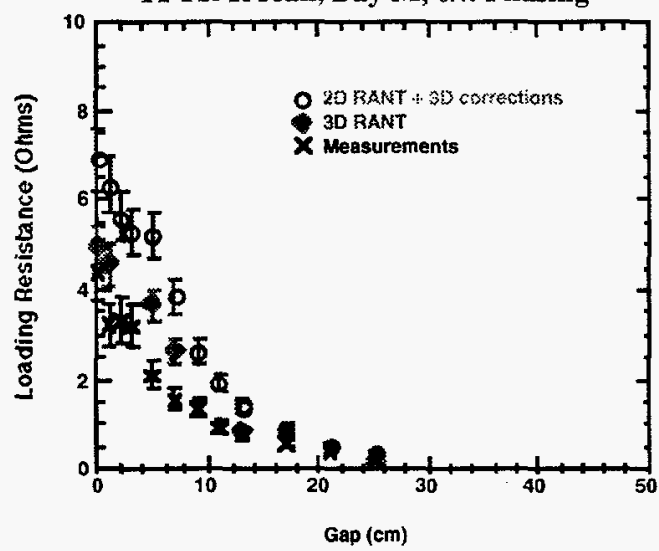

Fig. 4. Comparison of $2 \mathrm{D}$ and $3 \mathrm{D}$ models using RANT3D with measured loading resistance for dipole phasing.

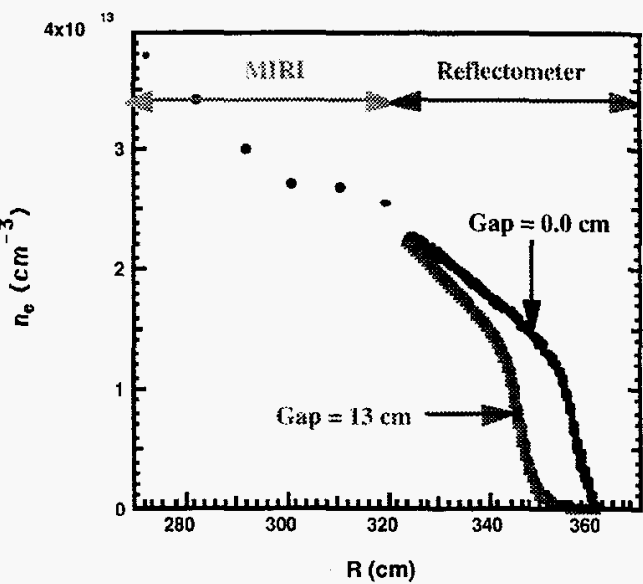

Fig. 3. Plasma density profiles for two different plasma positions as measured by a microwave reflectometer.

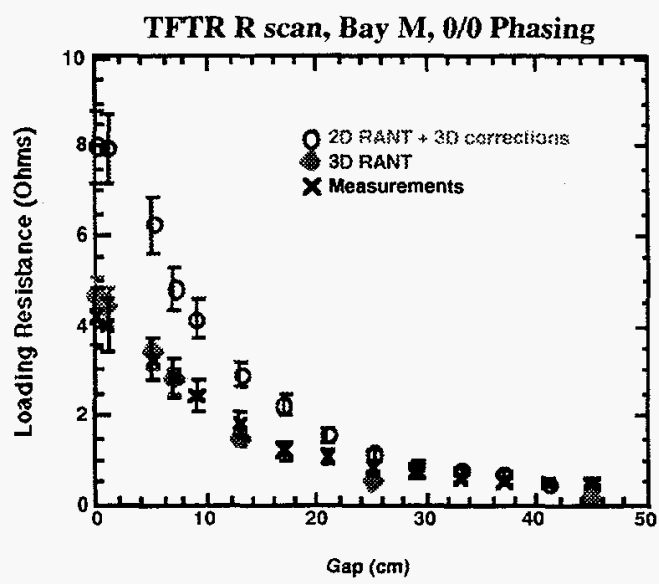

Fig. 5. Comparison of $2 D$ and $3 D$ models using RANT3D with measured loading resistance for monopole phasing.

Fig. 4 shows that, although both are systematically high, the 3D analysis more closely agrees with the measured loading than does the 2D analysis, particularly at the smaller plasma gaps where the mutual interaction between the plasma currents: and the return currents in the antenna frame is more pronounced. This discrepancy between the $2 \mathrm{D}$ and $3 \mathrm{D}$ results for small plasma gaps is even more noticeable for the monopole phasing in Fig. 5. In dipole phasing, the oppositely directed strap 
currents reduce the influence of the return currents, particularly those in the septum. In monopole phasing, the influence of the return currents on the loading and power spectrum is increased and both a $3 \mathrm{D}$ model and surrounding recesses are required for accurate calculations.

\section{JET A2 Flatbed Antenna Analysis}

Two JET A2 flatbed antenna modules, each consisting of two toroidally separated straps, were provided to ORNL by the JET ICH team for the purposes of measurement and analysis. These full-scale mockups are simplified versions of

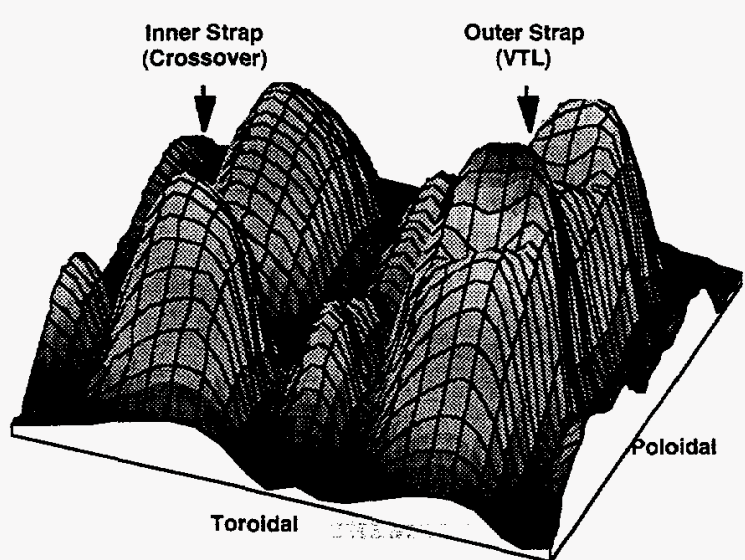

Fig. 6. Toroidal component of the if magnetic field $\left(\left|B_{Z}\right|\right)$ measured $1.5 \mathrm{~cm}$ in front of the flatbed antenna. the JET A2 antennas[15]. To facilitate fabrication, the mockup geometry is rectilinear rather than the complex curved geometry employed by the actual A2 antennas; gap spacing between the straps and the walls are changed, as is the detailed geometry of the power feed to the inner strap. Hence the detailed electrical characteristics of flatbed antennas differ somewhat from those of the actual A2 antennas. Nonetheless, all the general geometric characteristics of the actual antennas are present in the flatbed antenna.

A 3D model of the flatbed antenna was constructed for the ARGUS code. The model simplifies the antenna geometry to a further extent, decreasing the $15^{\circ}$ angle that matched the structure and Faraday shield elements to the magnetic field lines to $0^{\circ}$ for alignment with the code's Cartesian grid. The corrugated back walls were approximated with smooth walls and the gap spacing between the slanted rear sections of the straps and the slanted rear walls varied stepwise due to the finite grid. Although these approximations prevented accurate calculation of the port impedances, the electromagnetic field distribution in the vicinity of the radiating sections of the straps was duplicated quite well. Fig. 6 shows the magnitude of the toroidal component of the magnetic field measured $1.5 \mathrm{~cm}$ in front of the antenna for $35 \mathrm{MHz}$ and monopole phasing. Fig. 7 shows the calculated magnetic field pattern for $44 \mathrm{MHz}$, displaying the same

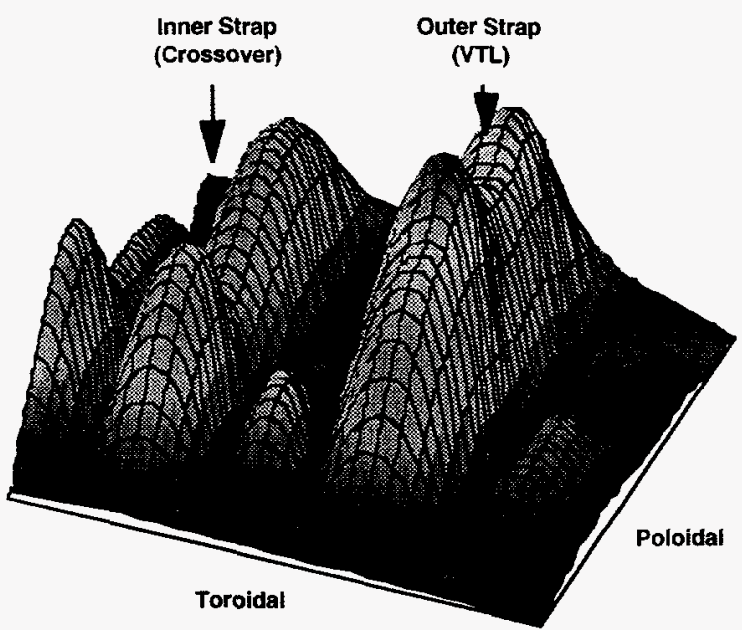

Fig. 7. Calculated $\left|B_{Z}\right| 1.5 \mathrm{~cm}$ in front of the model of the flatbed antenna. 
general characteristics. The circular depressions in the VTL (outer) strap peaks are caused by donut structures in the strap; although present in the model as well, their effect is not apparent since no radius of curvature was applied to them, as can be seem in Fig. 8.

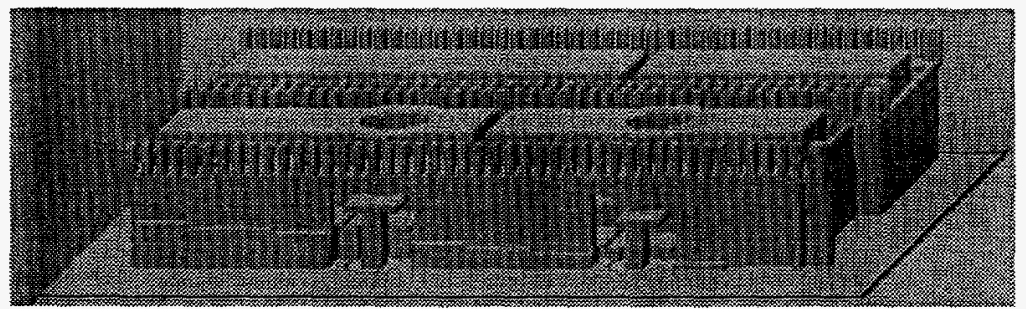

Fig. 8. ARGUS model of the JET A2 flatbed antenna.

To model the electrical response of the A2 flatbed antenna, each strap was subdivided into approximately two dozen sections. The electrical characteristics of each section, including internal coupling to other sections of the same strap, were calculated with a magnetostatic code and used as input parameters to the ANTMOD code. The calculated scattering parameters were compared to those measured with a network analyzer and an rf load consisting of absorbent material placed in front of the antenna. Fig. 9 shows the magnitude and phase of the calculated and measured reflection coefficients $S_{11}$ (outer strap) and $S_{22}$ (inner strap). In addition to the agreement with measurements over more than two octaves of frequency, it is apparent that the differences between the inner and outer strap geometry result in inner/outer line load imbalances over the frequency range of interest ( 23 to $57 \mathrm{MHz}$ ) when presented with identical loads. Fig. 10 shows the transmission coefficient $S_{12}$, representing the frequency dependence of the power transmission between inner and outer straps.
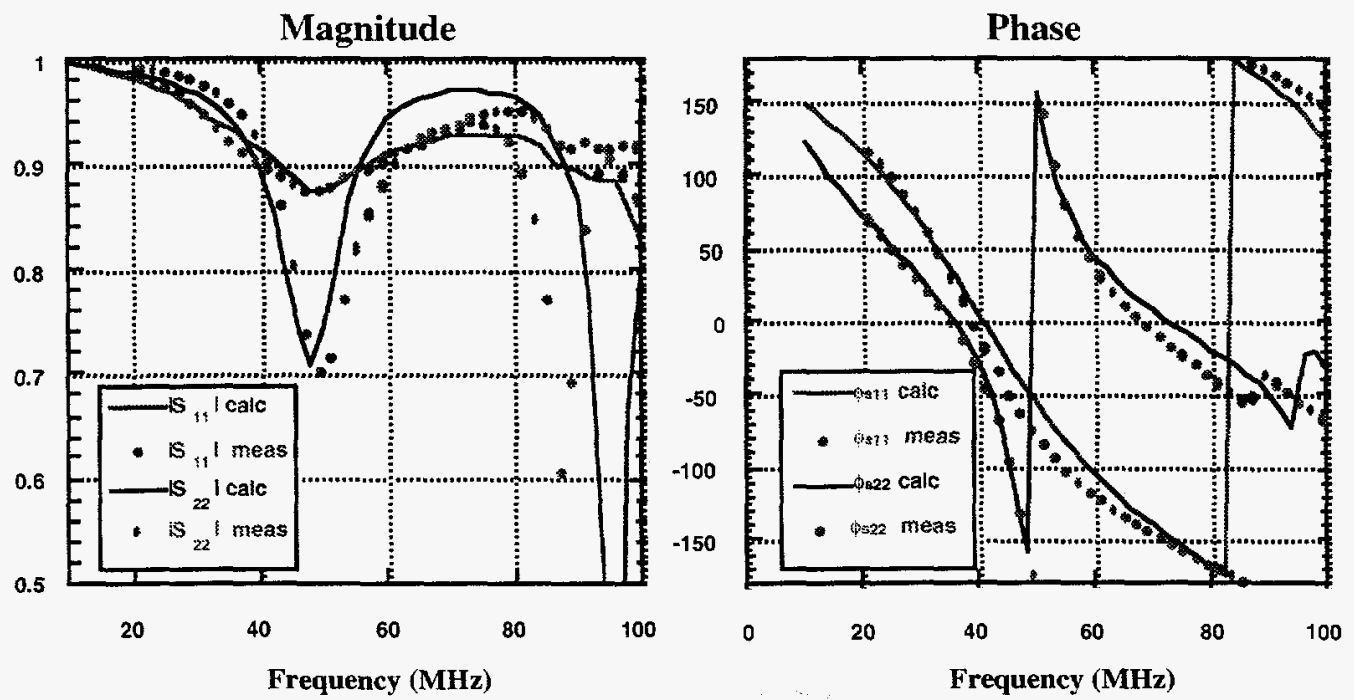

Fig. 9. Comparison of the measured scattering parameters (reflection coefficients) $S_{11}$ and $S_{22}$ with ANTMOD calculations. 

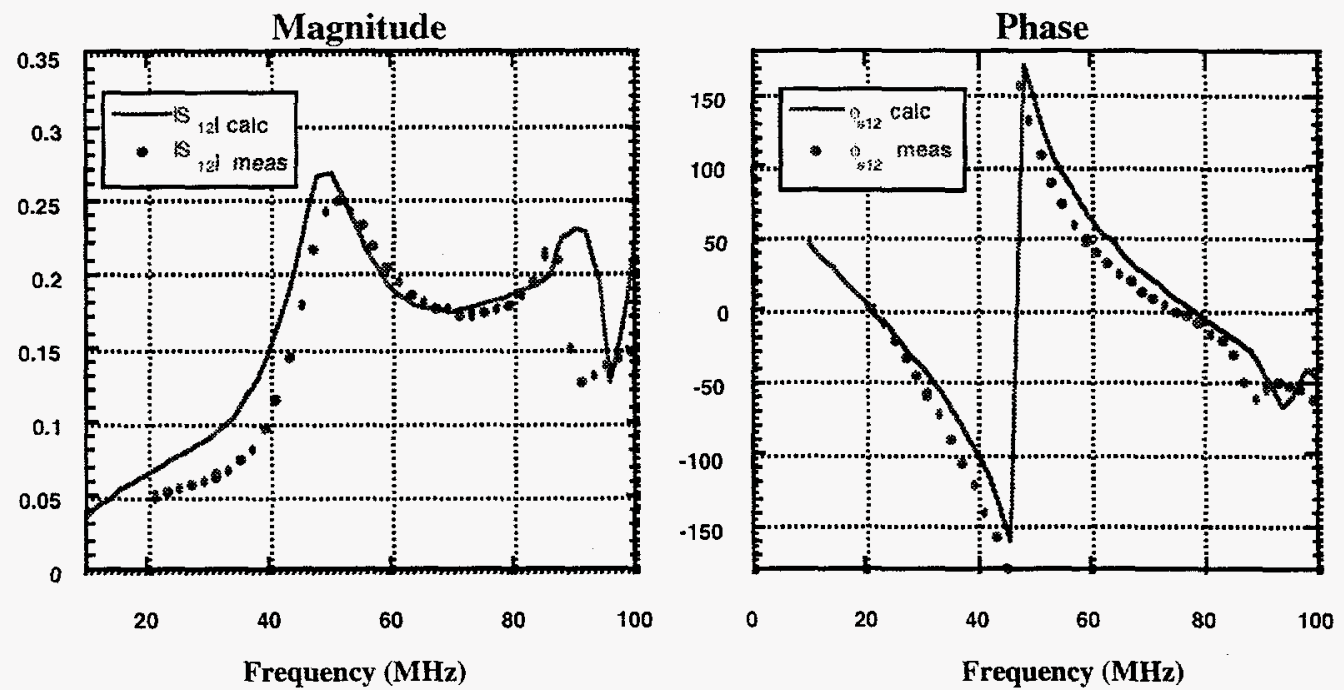

Fig. 10. Comparison of the measured scattering parameter (transmission coefficients) $\mathrm{S}_{12}$ with ANTMOD calculations.

\section{Design Example: TPX ICH System}

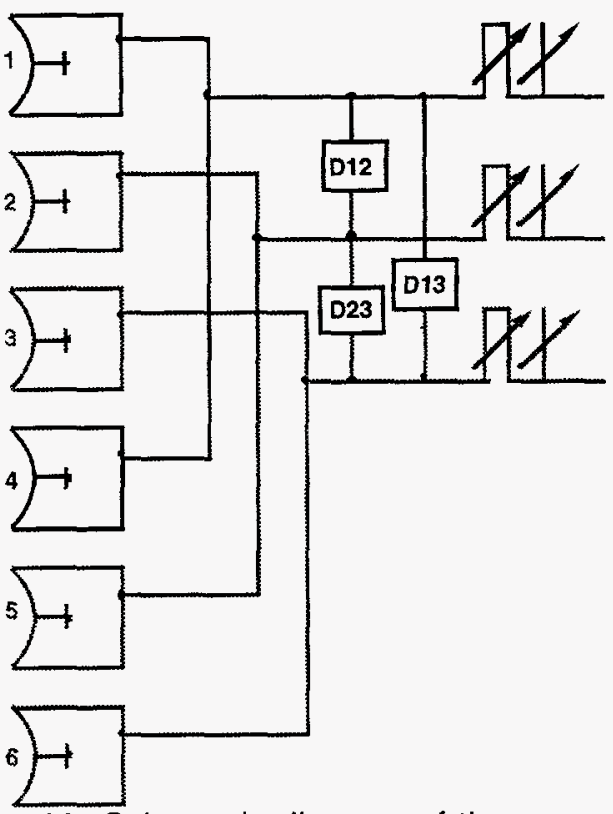

Fig. 11. Schematic diagram of the power distribution system for the TPX $\mathrm{ICH}$ antenna array.
An example chosen to demonstrate the use of the FDAC code is the Tuning and Matching network for the TPX ICH system, shown schematically in Fig. 11. The system consists of six centergrounded, end-fed antennas that form a toroidal array. Each antenna forms part of an inner loop, resonant at the frequencies of 45,61 , and $78 \mathrm{MHz}$ and fed at a high impedance tap point. The antennas are grouped in pairs and connected $180^{\circ}$ out of phase by an outer resonant loop; each pair is powered by one $2 \mathrm{MW}$ transmitter. The transmitters are matched to their loads by standard phase shifter/stub tuner elements and are isolated from one another by three decouplers positioned on the unmatched (antenna) side. Fast phase shifting is performed by the varying the phase of the transmitters, and fast tuning and matching uses plasma position control and frequency shifting.

The antenna array design was analyzed in a similar manner to that described for the TFTR antennas. Fig. 12 shows the wave spectra for relative phases between the transmitters of $0^{\circ}, 20^{\circ}$, and $60^{\circ}$; the array directivity can be continuously varied between -0.85 and +0.85 for current drive control. 


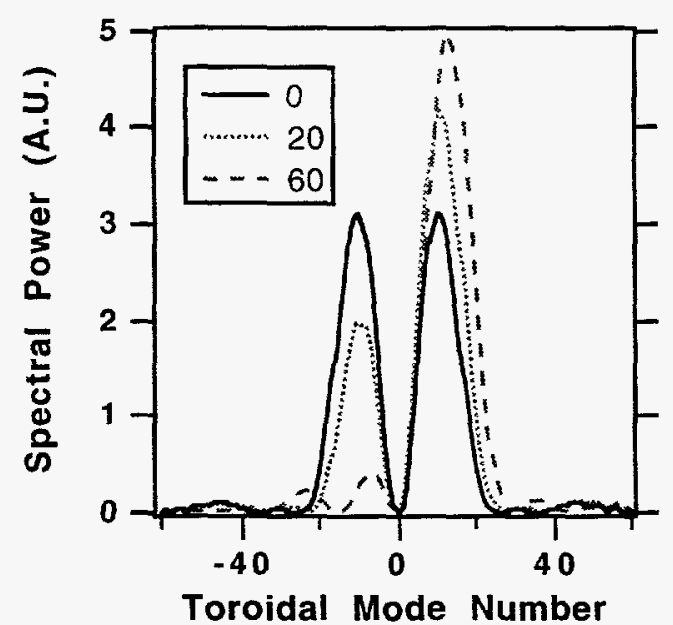

Fig. 12. Wave spectra for TPX antenna array for relative phase between transmitters of 0 , 20 , and 60 degrees.

elements. The strap pairs are connected to hybrid splitters and driven $90^{\circ}$ out of phase; common mode reflected power is routed to the dummy load rather than the transmitter. Fig. 13 shows the calculated response to assumed 10:1 antenna load variations. The reflection coefficient at the transmitters remains below 0.1 and $85 \%$ of the transmitter power is coupled to the antennas, on average.

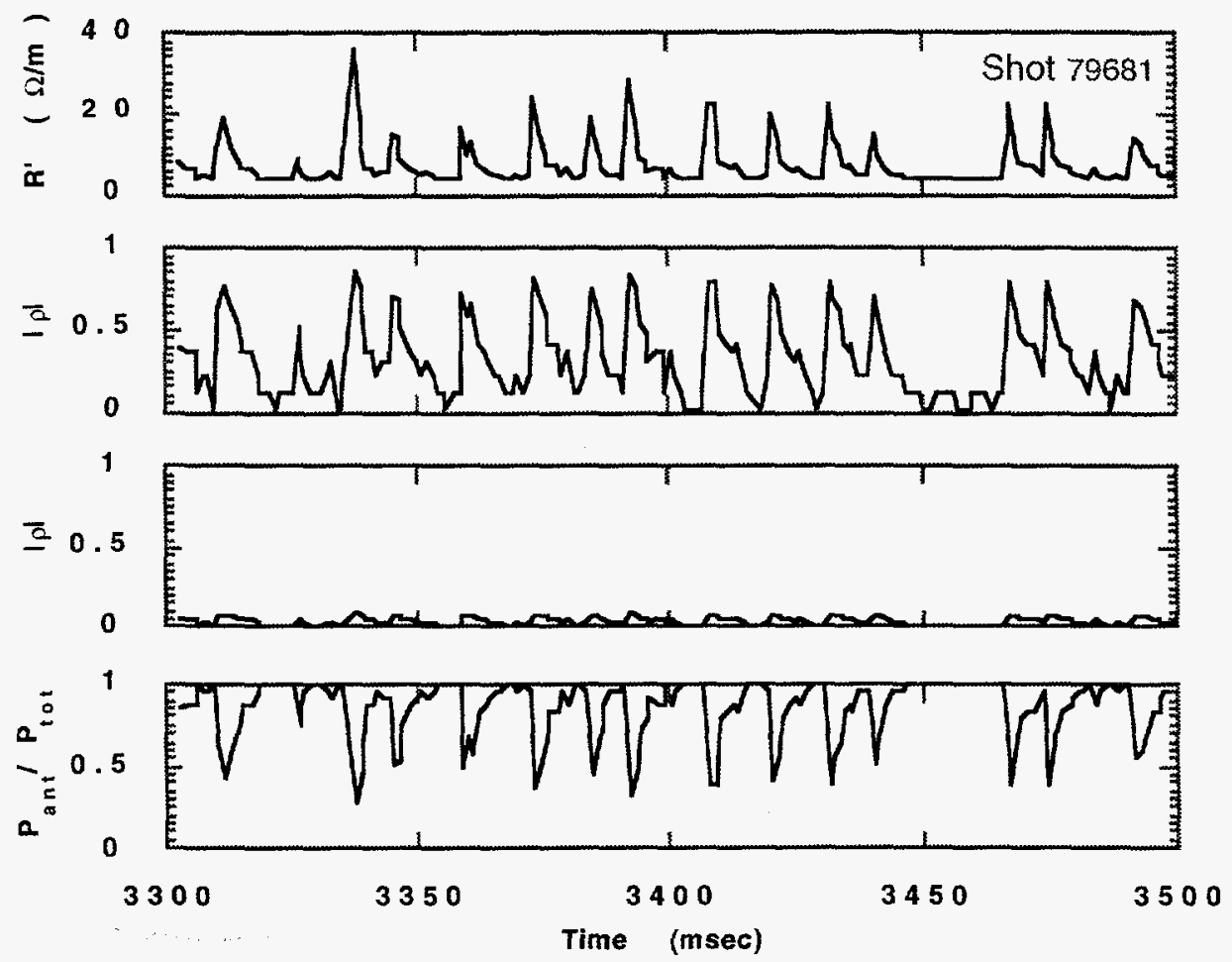

Fig. 13 Response of ITER ELM-handling concept, showing (a) assumed load variation during ELMs (from DIII-D) (b) reflection coefficient at the antenna, (c) reflection coefficient at the transmitter, (d) fraction of input power coupled to the antennas. 


\section{Conclusions}

Calculations of ICH plasma loading have progressed from relative scaling of measured loading to accurate predictions of absolute values. This has come about through more detailed plasma density profile information at the edge, the development of 3D antenna models for plasma interaction, and application of accurate electrical models of antennas to transform plasma loading calculations into measured values. Complex antenna geometries can be treated and their electrical response can be integrated into the overall response of the power distribution system. This increases the confidence to design rf systems for TPX and ITER.

\section{Acknowledgments}

Gratitude is extended to R. Prater and the General Atomic RF Group for the DIII-D antenna loading data (shot 79681) used for the analysis in Fig. 13.

\section{References}

[1] Goulding, R. H., Bhatnagar, V., Bosia, G., Hoffman, D. J., Ryan, P. M., Wade, T. J., Fusion Tech. 1992 (Proc. 17th Symp. on Fusion Tech, Rome, Italy, Sept, 1992), C. Ferro, M. Gasparotto, H. Knoepfel, ed. (Elsevier Science Publishers, 1993) 515

[2] Ryan, P. M., Goulding, R. H., Bhatnagar, V., Kaye, A., Wade, T., 10th Top. Conf. on RF Power in Plasmas, AIP Conf. Proc. 289 (Boston, MA, 1993) 355

[3] Goulding, R. H., Hoffman, D. J., Ryan, P. M., Bhatnagar, V., Bures, M., Dobbing, J. A., Start, D. F. H., Wade, T. J., Bull. Am. Phys. Soc. 38 (St. Louis, MO, 1993) 2107

[4] Goulding, R. H., Hoffman, D. J., Ryan, P. M., "Global ICRF System Designs for ITER and TPX", IIth Top. Conf. on RF Power in Plasmas, (Palm Springs, CA, 1995).

[5] Ryan, P. M., Baity, F. W., Goulding, R. H., Haste, G. R., Hoffman, D. J., Rothe, K. E., Whealton, J. H., Fusion Engrg. Des. 24 (1994) 135

[6] Carter, M. D., Rasmussen, D. A., Ryan, P. M.. Hanson, G. R., Stallings, D. C., Batchelor, D. B., Bigelow, T. S., England, A. C., Hoffman, D. J., Murakami, M., Wang, C. Y., Wilgen, J., Rogers, J. H., Wilson, J. R., Majeski, R., Schilling, G., to be published in Nucl. Fusion

[7] Stallings, D. C., Batchelor, D. B., Wang, C. Y., Carter, M.. D., Bull. Am. Phys. Soc. 39 (1994) 1628.

[8] Wang, C. Y., Batchelor, D. B., Jaeger, E. F., Carter, M. D., ORNL TM-12923 (Feb. 1995)

[9] Jaeger, E. F., Batchelor, D. B., Stallings, D. C., Nucl. Fusion 33 (1993) 179

[10] Ho, Y. L., Grossman, W., Drobot, A., Carter, M. D., Ryan, P. M., Batchelor, D. B., 10th Top. Conf. on RF Power in Plasmas, AIP Conf. Proc. 289 (Boston, MA, 1993) 359

[11] D'Ippolito, D., Myra, J., Majeski, R., Wilson, J. R., Ho, Y. L., Bull. Am. Phys. Soc. 39 (1994) 1627

[12] Wilson, J. R., Bialek, J., Bonanos, J., Brookes, A., Colestock, P. L., Hosea, J. C., Lehrman, I. S., Ritter, R., 7th Top. Conf. on RF Power in Plasmas, AIP Conf. Proc. 159 (Kissimmee, FL, 1987) 294

[13] Rogers, J. H., Majeski, R., Wilson, J. R., Hosea, J. C., Schilling, G., Stevens, J., Rasmussen, D. A., 10th Top. Conf. on RF Power in Plasmas, AIP Conf. Proc. 289 (Boston, MA, 1993) 359

[14] Wilgen, J. B., Hanson, G. R., Bigelow, T. S., Batchelor, D. B., Collazo, I., Hoffman, D. J., Murakami, M., Rasmussen, D. A., Stallings, D. C., 10th Top. Conf. on RF Power in Plasmas, AIP Conf. Proc. 289 (Boston, MA, 1993) 437

[15] Kaye, A., Brown, T., Bhatnagar, V., Crawley, P., Jacquinot, J., Lobel, R., Plancoulaine, J., Rebut, P.-H., Wade, T., Walker, C., Fusion Engrg. Des. 24 (1994) 1 